\title{
Delayed Fetal Pulmonary Maturation in a Rabbit Model of the Diabetic Pregnancy
}

\author{
Carl L. Bose, Diane N. Manne, A. Joseph D’Ercole, and Edward E. Lawson, \\ Department of Pediatrics, University of North Carolina School of Medicine, \\ Chapel Hill, North Carolina 27514
}

\begin{abstract}
A B S T RAC T A rabbit model for the diabetic pregnancy was used to investigate the etiology of delayed pulmonary maturation observed in infants of diabetic mothers. Pregnant rabbit does were made glucose intolerant and insulinopenic by injection of alloxan, a pancreatic $\beta$-cell cytotoxin. At $28 \mathrm{~d}$ (term $\sim 31 \mathrm{~d}$ ) fetuses of these animals were hyperglycemic, but were not hyperinsulinemic and did not demonstrate tissue overgrowth. Fetal pulmonary maturity was assessed by measurement of pressure-volume relationships on the fetal lungs. Fetuses of glucose-intolerant does demonstrated less retention of air on deflation. Phospholipid components of pulmonary surfactant were assayed on fluid obtained from lavage of the fetal lungs. Levels of disaturated phosphatidylcholine (percent total-lavage phospholipids) were diminished in fetuses of glucose-intolerant does compared to control fetuses $(20.5 \pm 4.2$ vs. $38.0 \pm 4.3 \%$; $P<0.01)$. Lecithin/ sphingomyelin ratios were similar in both groups and phosphatidylglycerol was not detected in either group. There was a direct correlation between the percentage of alveolar disaturated phosphatidylcholine and retention of air on lung deflation. These findings suggest that in this model pulmonary instability was a result of diminished alveolar disaturated phosphatidylcholine, and this diminution did not result from fetal hyperinsulinemia.
\end{abstract}

\section{INTRODUCTION}

The infant of the diabetic mother (IDM) ${ }^{1}$ is predisposed to life-threatening aberrations in physiology. An increased risk for the development of the respiratory

Dr. D'Ercole is a Jefferson Pilot Fellow in Academic Medicine. Dr. Lawson is an Edward Livingston Trudeau Fellow of the American Lung Association. Address requests for reprints to Dr. Lawson.

Received for publication 13 November 1979 and in revised form 7 March 1980.

1 Abbreviations used in this paper: DSPC, disaturated phosphatidylcholine; IDM, infant of the diabetic mother; L/S, lecithin to sphingomyelin; PG, phosphatidylglycerol; RDS, respiratory distress syndrome. distress syndrome (RDS) is one manifestation of these aberrations. Gellis and Hsia (1) originally reported the association of maternal diabetes and RDS. Their findings were confirmed in a more recent report by Robert and co-workers (2) who demonstrated that RDS occurred 5.6 times more frequently in IDM than in infants of nondiabetics.

Diminished alveolar surfactant is the principal cause of RDS in premature infants (3). Although surfactant is composed of a variety of substances, its phospholipid content has attracted the most research interest. Certain phospholipids, particularly the lecithins, have the capacity to achieve the low surface tensions necessary to stabilize alveoli in the newborn lung. Therefore, estimation of fetal pulmonary lecithin production by measurement of the lecithin to sphingomyelin ratio in amniotic fluid is used as an index of fetal pulmonary maturity (4). Although this measure is highly predictive of lung maturation in normal pregnancies, it is peculiarly unreliable in the diabetic pregnancy (5). This finding suggests that maternal diabetes interferes with fetal pulmonary maturation without affecting total lecithin synthesis.

Disaturated lecithin (disaturated phosphatidylcholine: DSPC) is the lecithin with the greatest capacity to lower surface tension (6) and quantitatively is the predominate lecithin in pulmonary surfactant (7). It is possible that the relative proportion of DSPC is diminished in pulmonary surfactant of the IDM without change in total lecithin. To investigate the possibility that alterations exist in pulmonary phospholipid content in the IDM, we have used the alloxantreated pregnant rabbit as a model for diabetes during pregnancy $(8,9)$. Fetuses of glucose-intolerant rabbit does were found to have changes in pulmonary dynamics consistent with the pulmonary immaturity seen in IDM, and these changes were associated with diminished alveolar DSPC.

\section{METHODS}

Animals and experimental design. New Zealand white rabbit does were bred with the time of mating known to within 
$3 \mathrm{~h}$. Diabetes was induced by intravenous injection of alloxan (2,4,5,6-tetraoxypyrimidine; 5,6-dioxyuracil; Sigma Chemical Co., St. Louis, Mo.), a pancreatic $\beta$-cell cytotoxin. Does were treated with a total dose of between 60 and $130 \mathrm{mg} / \mathrm{kg}$ : half given at $48 \mathrm{~h}$ after mating and the remainder at $72 \mathrm{~h}$ after mating. Of the 62 mated rabbits that were injected with alloxan, 13 were hyperglycemic (serum glucose $>150 \mathrm{mg} / \mathrm{dl}$ ) during gestation and were pregnant at sacrifice. Of the remaining 49 rabbits, 26 died after injection. 17 of the surviving rabbits remained euglycemic. Six of the injected, nonstudy animals developed glucose intolerance, two delivered spontaneously before $28 \mathrm{~d}$ gestation, and four were not pregnant at sacrifice. 10 control animals were mated and studied concurrently. Maternal blood was collected weekly until sacrifice. Immediately after collection the blood was chilled at $4^{\circ} \mathrm{C}$ and after clot formation, the serum was separated and frozen.

Control and alloxan-treated does were sacrificed at $28 \mathrm{~d}$ gestation (term 31 d) by intravenous injection of $300 \mathrm{mg}$ of pentobarbital. The fetuses were immediately delivered within their amniotic sacs by hysterotomy and injected intraperitoneally with $30 \mathrm{mg}$ of pentobarbital before removal of the amniotic membranes. Though an occasional animal gasped, none breathed air before death. Alternate pups were exsanguinated by direct cardiac puncture as soon as possible $(<10 \mathrm{~min})$. The serum was chilled, separated, and stored. The crown-rump length and weight of these pups were recorded, and their lungs, liver, heart, brain, kidneys, and placentae were removed and weighed.

Pulmonary function measurements. Quasi-static pressure/ volume measurements were performed on the lungs of the remaining pups by the technique of Kotas and Avery (10). After weighing and measuring of the pup, the trachea was cannulated with a polyethylene catheter (Clay-Adams, Div., Becton, Dickinson \& Co., Parsippany, N. J.) with the lungs remaining in situ. The lungs were then inflated with air and allowed to stabilize at a distending pressure of $30 \mathrm{~cm}$ of water. This was defined as maximum lung volume. The pressure was then lowered by scheduled increments allowing ample time (1-2 min) for stabilization at each deflation pressure. The residual volume at each pressure was recorded and expressed as a percentage of maximum lung volume.

Collection of surfactant. The lungs were then lavaged five times with a volume of saline equal to $75 \%$ of the maximum lung volume. Specimens were considered unreliable and discarded if $<70 \%$ of the lavage fluid was recovered or they were grossly contaminated with blood. The five washings from each pup were pooled and centrifuged at $500 \mathrm{~g}$ for $5 \mathrm{~min}$. The supernate was collected and the lipid fraction was extracted using two parts chloroform and one part methanol to one part supernate. The aqueous phase was separated and removed, and the lipid phase was washed with theoretical upper phase (chloroform/methanol/water, 3:48:47, $\mathrm{vol} / \mathrm{vol} / \mathrm{vol}$ ) (11). The lipid extract was then stored at $-20^{\circ} \mathrm{C}$.

Glucose, ketone, and insulin assays. Serum glucose was determined using the hexokinase-glucose-6-phosphate dehydrogenase reaction (Gluco Strate, General Diagnostics Warner Lambert Co., Morris Plains, N. J.) (12). The presence of ketones was semi-quantitatively determined using Acetest reagent tablets (Ames Co., Elkhart, Ind.). One animal became ketotic and was prospectively excluded. Serum insulin concentrations were determined by double antibody radioimmunoassay using iodinated porcine insulin and a purified porcine insulin standard (13). The dose-response curves of rabbit serum paralleled those produced by the purified porcine insulin standard.

Phospholipid assay. The lipid extracts from the pups of each litter were pooled. Total lipid phosphorus was determined by the Bartlett technique (14). This spectrophotometric assay compared unknowns to a standard curve that was linear between 3.3 and $48.4 \mathrm{nmol}$ with a coefficient of variation of $\pm 11 \%(n=60)$.

A portion of each pooled specimen was reacted with osmium tetroxide (Fisher Scientific Co., Pittsburgh, Pa.) by the technique of Mason et al. (15). This technique has been demonstrated to oxidize essentially all the phospholipids with unsaturated fatty acid residues (16). Correction for DSPC loss during oxidation was determined by the addition of trace amounts of $\left[{ }^{14} \mathrm{C}\right]$ dipalmitoyl lecithin (New England Nuclear, Boston, Mass.) to each specimen. The oxidized and unoxidized fractions were separated by elution over an alumina column. The amount of DSPC present in the unoxidized fraction was below the lower limits of sensitivity of our phosphorus assay. Therefore, the unoxidized fraction was evaporated under nitrogen and the residue was resuspended in chloroform. Four aliquots in two concentrations were applied to silica gel plates impregnated with ammonium sulfate (Supelco, Inc., Bellefonte, $\mathrm{Pa}$.) and developed in chloroform/methanol/ ammonia (70:30:3, $\mathrm{vol} / \mathrm{vol})$. DSPC was visualized by charring $\left(200^{\circ} \mathrm{C}\right.$ for 30 min) and quantified using a dual beam reflectance densitometer (Schoeffel Instruments Div., Kratos, Inc., Westwood, N. J.). Quantities of DSPC were expressed as molar weights by comparing densitometric areas to a standard curve. This curve was generated using dipalmitoyl lecithin standard (Sigma Chemical Co.) and is linear between 0.27 and $2.72 \mathrm{nmol}$. The coefficient of variation of this standard curve is $\pm 12 \%(n=66)$, comparable to that of the standard curve of the phosphorus assay.

Phosphatidylglycerol (PG) was assayed by a modification of the technique reported by Rooney et al. (17). An aliquot of the pooled phospholipid fraction was spotted on ammonium sulfate impregnated silica gel plates and developed three times to 10 $\mathrm{cm}$ in tetrahydrofuran/methylal/methanol/2 $\mathrm{M}$ ammonia (10: $8: 2: 1: 1, \mathrm{vol} / \mathrm{vol}$ ), with drying in a $70^{\circ} \mathrm{C}$ oven between each run. The phospholipids were visualized by charring, and quantified by reflectance densitometry as above. This technique permitted quantitation of as little as $0.26 \mathrm{nmol}$ of PG.

Total lecithin/sphingomyelin $(\mathrm{L} / \mathrm{S})$ ratios were determined by spotting an aliquot of the pooled phospholipid fraction on ammonium sulfate impregnated silica gel plates. These were developed in chloroform/methanol/water $(65: 25: 4$, vol/vol); charred, and quantified by reflectance densitometry. Only the $\mathrm{L} / \mathrm{S}$ ratios were expressed as a ratio of densitometric areas.

Lavaged lungs were cleaned of all visible nonpulmonary tissue, dried in a $50^{\circ} \mathrm{C}$ oven for $48 \mathrm{~h}$, and weighed (18).

Statistics. In assessing the significance of differences in fetal data sets, the number used was the number of litters and the mean used was the mean of the average fetal value for each litter (19). All values are reported as mean \pm SEM. Except where noted, all statistical comparisons are done using the Student's $t$ test for unpaired variables.

\section{RESULTS}

The diabetic model. The 12 alloxan-treated nonketotic animals consistently showed clinical evidence of glucose intolerance, i.e., polydypsia and polyuria, but otherwise appeared healthy. The maternal serum glucose and insulin at 21 and $28 \mathrm{~d}$ are depicted in Table I. The mean serum glucose of treated animals was significantly greater than that of the control animals. Maternal serum insulin levels were similar at $21 \mathrm{~d}$, but were significantly lower in the treated animals at $28 \mathrm{~d}$. However, at both 21 and $28 \mathrm{~d}$ the glucose/insulin ratio 
TABLE I

Glucose, Insulin, and Glucose/Insulin Ratio in Maternal Rabbits

\begin{tabular}{|c|c|c|c|c|c|c|}
\hline \multirow[b]{2}{*}{ Gestational period, $d$} & \multicolumn{2}{|c|}{ Glucose* } & \multicolumn{2}{|c|}{ Insulin $\downarrow$} & \multicolumn{2}{|c|}{ Glucose/insulin* } \\
\hline & 21 & 28 & $2 \mathrm{i}$ & 28 & 21 & 28 \\
\hline & \multicolumn{2}{|c|}{$m g / d l$} & \multicolumn{2}{|c|}{$\mu U / m l$} & & \\
\hline $\begin{array}{l}\text { Control } \\
(n=10)\end{array}$ & $\begin{array}{r}111.8 \\
\pm 13.2\end{array}$ & $\begin{array}{r}103.1 \\
\pm 9.1\end{array}$ & 12.3 & 22.1 & $\begin{array}{r}9.5 \\
\pm 2.9\end{array}$ & $\begin{array}{r}5.6 \\
\pm 1.2\end{array}$ \\
\hline $\begin{array}{l}\text { Alloxan-treated } \\
(n=12)\end{array}$ & $\begin{array}{r}316.0 \\
\pm 32.2\end{array}$ & $\begin{array}{r}246.7 \\
\pm 39.3\end{array}$ & 11.3 & 6.8 & $\begin{array}{r}32.1 \\
\pm 7.5\end{array}$ & $\begin{array}{r}30.4 \\
\pm 7.3\end{array}$ \\
\hline$P$ value & $<0.001$ & $<0.01$ & NS & $<0.01 \S$ & $<0.02$ & $<0.01$ \\
\hline
\end{tabular}

was significantly increased in treated does compared to controls. This value reflects the secretory response of the pancreas to serum glucose levels at single points in time. Therefore, it appears that alloxan-treated does were unable to respond to hyperglycemia with expected levels of insulin.

Fetal glucose levels were significantly elevated in the pups of diabetic does (Table II), presumably a reflection of maternal hyperglycemia at the time of sacrifice. Fetal insulin levels, however, did not vary between the control and treated groups. Likewise, no difference existed between fetal insulin levels from litters of mildly diabetic $(28 \mathrm{~d}$ glucose $<200 \mathrm{mg} / \mathrm{dl})$ and severely diabetic $(28 \mathrm{~d}$ glucose $>200 \mathrm{mg} / \mathrm{dl})$ does (53.8 \pm 9.6 vs. $49.1 \pm 10.6 \mu \mathrm{U} / \mathrm{ml})$. Glucose/insulin ratios, however, were elevated in the fetuses of alloxantreated animals, suggesting that fetal hyperglycemia did not elicit increased insulin secretion.

Fetuses of glucose-intolerant does did not demonstrate tissue overgrowth. There were no significant differences between fetuses in control and alloxantreated litters in average body weight, crown-rump length, placental weight, and weights of the liver, lungs, heart, brain and kidneys, expressed as a percentage of body weight (Table III).

TABLE II

Glucose, Insulin, and Glucose/Insulin Ratio in Fetal Rabbits*

\begin{tabular}{lccc}
\hline & Glucose & Insulin & Glucose/insulin \\
\hline & $m g / d l$ & $\mu U / m l$ & \\
Control & 65.8 & 48.1 & 1.6 \\
$(n=10$ litters $)$ & \pm 7.9 & \pm 4.3 & \pm 0.4 \\
Alloxan-treated & 187.6 & 51.4 & 4.5 \\
$(n=12$ litters $)$ & \pm 37.4 & \pm 6.8 & \pm 1.0 \\
$P$ value & $<0.01$ & $\mathrm{NS}$ & $<0.05$ \\
\hline
\end{tabular}

* All values mean $\pm \mathrm{SEM}$; 28 -d gestation.
There were seven late gestation fetal deaths in the treated litters and none in the control litters. Two major congenital anomalies were observed, both in diabetic pregnancies. One pup had a gastroschisis and the other had arthrogryposis-like skeletal anomalies. Both of these animals were prospectively excluded from the study.

Pulmonary maturation. Results of pressure-volume measurements are depicted in Fig. 1. Percentage of retained air was significantly less in the treated litters at $0,3,5,7,10$, and $15 \mathrm{~cm} \mathrm{H}_{2} \mathrm{O}$. The absolute amount of lavage DSPC was diminished in treated litters (154 \pm 41 $\mathrm{nmol} / \mathrm{g}$ dry lung) compared with controls (248 \pm 61 $\mathrm{nmol} / \mathrm{g}$ dry lung). However, the large amount of variability in these values suggests the need for an internal standard. Therefore, quantities of DSPC from each litter were expressed as a percentage of the total phospholipid phosphorus (nmol DSPC/nmol P $\times 100$ ). The percentage of DSPC in fluid from control litters was significantly greater than the percentage of DSPC in treated litters $(38.0 \pm 4.3$ vs. $20.5 \pm 4.2 \% ; P<0.01$; Fig. 2). The relationship between percent DSPC and air retention on deflation at $10 \mathrm{~cm} \mathrm{H}_{2} \mathrm{O}$ was similar for both treated and control litters. This linear relationship is illustrated in Fig. 3 by a common regression line $(r=0.75, P<0.01)$. A similar correlation was observed at each of the deflation pressures from 0 to $15 \mathrm{~cm} \mathrm{H}_{2} \mathrm{O}$. PG was not detected in any of the specimens and therefore, if present at all, represented $<2 \%$ of the total phospholipids. There was no significant difference between the mean of the $\mathrm{L} / \mathrm{S}$ ratios of tracheal lavage fluid from fetuses of control $(2.69 \pm 0.32)$ and alloxantreated $(2.26 \pm 0.49)$ litters.

\section{DISCUSSION}

In this model for the diabetic pregnancy, premature pups from glucose-intolerant does had significantly altered pulmonary dynamics when compared to age- 
TABLE III

Fetal Growth Data*

\begin{tabular}{lcccccrrrr}
\hline & $\begin{array}{c}\text { Litter } \\
\text { size }\end{array}$ & $\begin{array}{c}\text { Fetal } \\
\text { wt }\end{array}$ & $\begin{array}{c}\text { Crown-rump } \\
\text { length }\end{array}$ & $\begin{array}{c}\text { Placental } \\
\text { wt }\end{array}$ & $\begin{array}{c}\text { Liver } \\
\text { wt }\end{array}$ & $\begin{array}{c}\text { Lung } \\
\text { wt }\end{array}$ & \multicolumn{1}{c}{$\begin{array}{c}\text { Heart } \\
\text { wt }\end{array}$} & $\begin{array}{c}\text { Brain } \\
\text { wt }\end{array}$ & $\begin{array}{r}\text { Kidney } \\
\text { wt }\end{array}$ \\
\hline & & $\mathrm{g}$ & $c m$ & $\mathrm{~g}$ & & & $\%$ body wt & & \\
Control & 7 & 33.42 & 8.5 & 3.29 & 6.38 & 3.09 & 0.55 & 2.64 & 0.92 \\
$(n=10$ litters $)$ & \pm 1 & \pm 2.19 & \pm 0.2 & \pm 0.23 & \pm 0.14 & \pm 0.12 & \pm 0.02 & \pm 0.10 & \pm 0.03 \\
Alloxan-treated & 8 & 28.65 & 8.1 & 3.09 & 6.57 & 3.15 & 0.55 & 2.65 & 0.85 \\
$(n=12$ litters $)$ & \pm 1 & \pm 1.62 & \pm 0.2 & \pm 0.19 & \pm 0.22 & \pm 0.15 & \pm 0.02 & \pm 0.11 & \pm 0.03 \\
$P$ value & $\mathrm{NS}$ & $\mathrm{NS}$ & $\mathrm{NS}$ & $\mathrm{NS}$ & $\mathrm{NS}$ & $\mathrm{NS}$ & $\mathrm{NS}$ & $\mathrm{NS}$ & $\mathrm{NS}$ \\
\hline
\end{tabular}

* All values mean $\pm \mathrm{SEM} ; 28$-d gestation.

matched controls. Lungs of these animals retained less air on deflation during pressure-volume measurements. DSPC represented a lesser portion of the total pulmonary lavage phospholipids in fetuses of hyperglycemic animals, and the percentage of DSPC varied directly with retained air on lung deflation. These findings indicate that maternal glucose intolerance is associated with significant alterations in fetal pulmonary development.

It is unlikely that the observed changes in pulmonary dynamics and phospholipid metabolism resulted from the effect of alloxan on the fetal animal. In the rabbit, ovulation occurs after mating, and fertilization does not occur until $12 \mathrm{~h}$ later. Implantation of the ova is delayed until $7 \mathrm{~d}$ of gestation (20). Since the serum half-life of alloxan is $<1 \mathrm{~min}(21)$, the drug would either be metabolized or entirely tissue-bound within $60 \mathrm{~h}$ of fertilization and several days before implantation, long before pancreatic (22) or pulmonary (23) tissue differentiation. Furthermore, although alloxan has been reported to

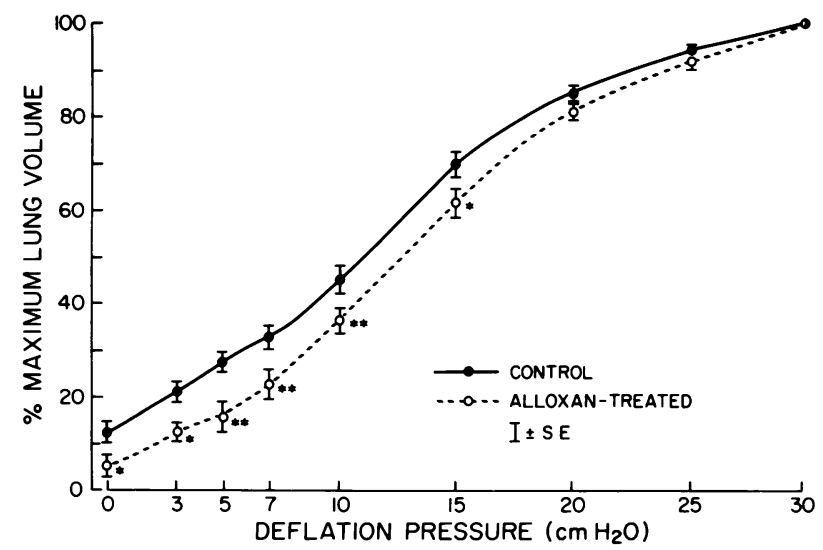

Figure 1 Mean pressure-volume data for fetuses of control $(n=10)$ and alloxan-treated $(n=12)$ litters. Lung volume on deflation is expressed as percentage of maximum lung volume. The fetuses of alloxan-treated does had significantly less retention of air at $0,3,5,7,10$, and $15 \mathrm{~cm} \mathrm{H}_{2} \mathrm{O}$ pressure $\left({ }^{*} P<0.05,{ }^{* *} P<0.01\right)$. cross the placenta, even diabetogenic maternal doses given later in gestation do not cause diabetes in offspring (24). The observed effects on the fetal rabbits then, may be assumed to be a result of influences other than alloxan on the fetal milieu.

Pulmonary stability assessed by measurement of pressure-volume relationships has been proposed as a functional index of fetal pulmonary maturity. Increased retention of air on deflation occurs in gestationally

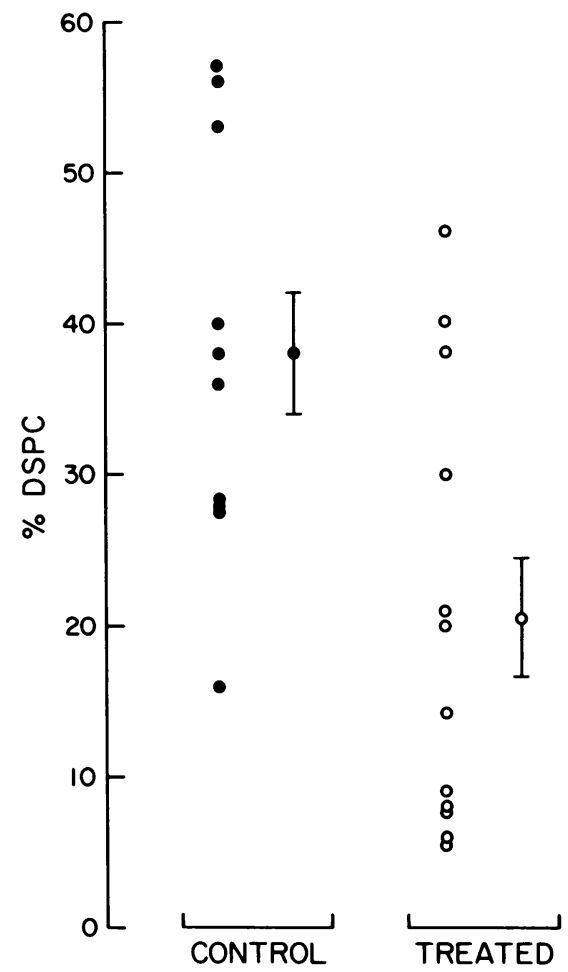

FIGURE 2 DSPC in pulmonary lavage expressed as percentage of total phospholipid phosphorus in control and alloxan-treated litters. The value of the pooled lavage specimen from each litter is illustrated as well as the mean \pm SEM of each group. The difference between the control and alloxan-treated means is significant $(P<0.01 ; n=22)$. 


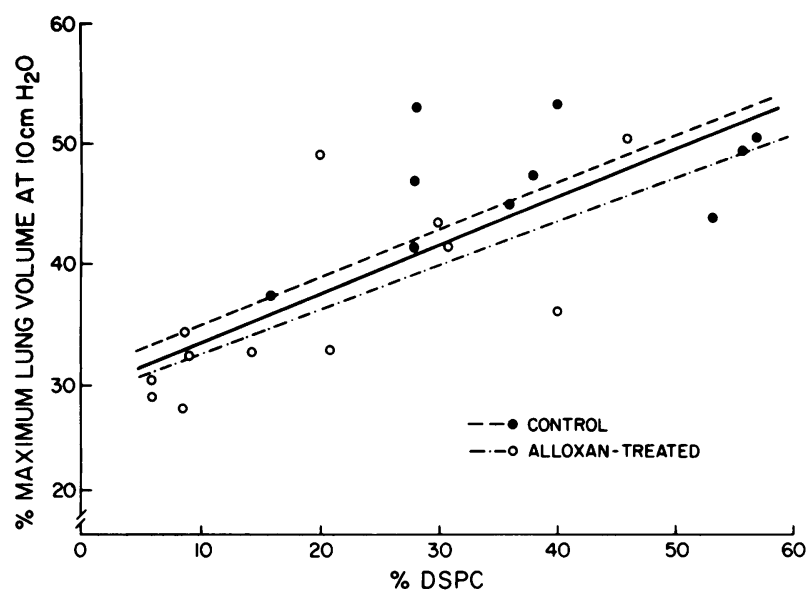

FIGURE 3 Relationship between percentage of DSPC in pulmonary lavage and the percentage of maximum lung volume retained at a deflation pressure of $10 \mathrm{~cm} \mathrm{H}_{2} \mathrm{O}$. The broken regression lines illustrate this relationship for control and alloxan-treated litters. These are not significantly different. The linear correlation for all litters is illustrated by the solid line and is significant $(r=0.75 ; P<0.01 ; n=22)$.

older fetal animals $(25,26)$ and is observed in fetuses with accelerated pulmonary maturation induced by exogenous steroids $(10,27)$. By contrast, human infants who succumb with RDS have diminished stability on deflation (28). Our finding that air retention is reduced in fetuses of glucose-intolerant does is comparable to findings reported by Sosenko and co-workers (9). Differences in pulmonary air retention at low pressures are presumed to be a result of altered alveolar surface forces and not changes in tissue elasticity (26). In the fetal lamb, increased quantities of surface-active material from alveolar washings have been associated with greater stability on deflation (25). In addition, increased air retention occurs coincident with the histologic appearance of increasing numbers of large alveolar cells with osmiophilic lamellar bodies, the intracellular storage form of surfactant (25). These findings suggest that reduced alveolar surfactant is the principal cause of diminished air retention in the fetuses of alloxan-treated litters.

Alveolar surfactant is composed of a mixture of phospholipids and at least one immunospecific protein. DSPC is the phospholipid present in highest concentration in pulmonary surfactant (7) and has the capacity to reduce surface tension and stabilize alveoli on deflation in the newborn lung (6). Phospholipids recovered by pulmonary lavage reflect those secreted into the alveolus. We assume that DSPC is removed by lavage with efficiency similar to all other alveolar phospholipids. However, absolute recovery of phospholipids may vary between and within litters. Therefore, quantities of DSPC are expressed as a percentage of total lavage phospholipids. This manner of expression tends to reduce variance induced by differences in recovery and has been used by other investigators when certainty about complete recovery is in doubt (29).

Percent DSPC in lavage fluid was significantly reduced in fetuses of glucose-intolerant does compared to controls $(P<0.01$; two-tailed $t$ test). It may be argued that the reduced ratio in treated litters is due to change in either the DSPC value or the total phospholipid value. Table IV demonstrates the absolute values for DSPC and total phospholipids (nmol/g dry lung) found in control and treated litters. The control DSPC value is $61 \%$ greater than the treated DSPC value, whereas the control total phospholipid value is $18 \%$ less than the value for treated litters. Evaluation of the distribution of absolute DSPC and phospholipid values about their respective medians suggests that DSPC values in treated litters are lower than in controls $\left(P<0.05 ; \chi^{2}\right.$; one-tailed), whereas phospholipid values in treated and control litters are evenly distributed around their median. Therefore, we conclude that the difference observed in the percent DSPC in treated and control litters is primarily due to

TABLE IV

Lavage Phospholipid Values

\begin{tabular}{|c|c|c|c|c|c|c|c|}
\hline & & \multicolumn{2}{|c|}{ DSPC } & \multicolumn{2}{|c|}{ Total phospholipid } & \multicolumn{2}{|c|}{ Percent DSPC } \\
\hline & & Control & $\begin{array}{l}\text { Alloxan- } \\
\text { treated }\end{array}$ & Control & $\begin{array}{l}\text { Alloxan- } \\
\text { treated }\end{array}$ & Control & $\begin{array}{l}\text { Alloxan- } \\
\text { treated }\end{array}$ \\
\hline & & \multicolumn{2}{|c|}{ nmol/g dry lung } & \multicolumn{2}{|c|}{ nmol/g dry lung } & & \\
\hline \multirow{3}{*}{$\begin{array}{l}\text { Bose et al. } \\
\text { (current study) }\end{array}$} & Mean & 248 & 154 & 608 & 737 & 38.0 & 20.5 \\
\hline & SEM & 61 & 41 & 111 & 115 & 4.3 & 4.2 \\
\hline & & \multicolumn{2}{|c|}{$P<0.05^{*}$} & \multicolumn{2}{|c|}{ NS } & \multicolumn{2}{|c|}{$P<0.01$} \\
\hline \multirow[t]{3}{*}{ Sosenko et al. } & Mean & 75 & 60 & - & - & - & - \\
\hline & SEM & 23 & 27 & & & & \\
\hline & & \multicolumn{2}{|c|}{ NS } & & & & \\
\hline
\end{tabular}

* One-tailed chi square. 
change in the DSPC value. On the other hand, Sosenko et al. (9) did not find a significant difference between absolute DSPC values in five control and five treated litters (Table IV). Their failure to find a significant difference may be solely due to the large variance about the mean. The reason for the large disparity between the absolute DSPC values of Sosenko et al. and those of the present study is unknown, but probably due to technical differences between the two studies. Quantities of lavage phospholipids in 28-d control fetuses observed in the present study are similar to those reported $(30,31)$.

PG has also been shown to have surface-active properties (32), and its absence has been implicated by some investigators in the etiology of RDS in the IDM (33). PG was not detected in lavage fluid from either treated or control litters. Likewise, the $\mathrm{L} / \mathrm{S}$ ratios were similar in treated and control litters. The diminished levels of DSPC observed in lavage fluid from treated litters and the positive correlation between retention of air and percent DSPC therefore suggest that the alterations in the physical properties of the fetal lungs may be entirely a result of diminished concentrations of alveolar DSPC. Although the mechanism for this diminution remains unclear, we postulate that the delayed functional development of surfactant observed in many IDM may be due to diminished alveolar concentrations of DSPC.

Several investigators have used in vitro models to study the manner by which the diabetic milieu exerts its effect on phospholipid metabolism. Smith et al. (34) examined the rate of choline incorporation into lecithin in type II pneumonocytes in cell culture under the influence of insulin and cortisol. They found that insulin inhibited the stimulatory effect of cortisol on lecithin synthesis. This finding implies that the hyperinsulinemia observed in IDM (35) inhibits the effect of endogenous corticosteroids on fetal pulmonary lecithin synthesis. Similarly, Gross and Smith (36) demonstrated delayed morphologic maturation of type II cells and delayed appearance of lamellar osmiophilic bodies in the presence of high insulin levels in rat lung organ culture. In this study fetuses of treated animals did not demonstrate hyperinsulinism. Fetal serum glucose levels, however, were elevated at the time of sacrifice; and since maternal glucose levels were significantly elevated earlier in gestation, it is presumed that fetal hyperglycemia was relatively long standing. Therefore, the diminished levels of DSPC observed in alloxan-treated litters may be due to the effects of hyperglycemia rather than alterations in insulin levels. This hypothesis is supported by the recent report of Sosenko et al. (37) who found that cord blood levels of Cpeptide, the by-product of the cleavage of proinsulin to insulin, were increased in IDM who were macrosomic or had postnatal hypoglycemia. However, they found no correlation between cord blood C-peptide and the presence of RDS in the IDM.

Assessment of fetal pulmonary phospholipid synthesis has been approximated by measurement of surfactant components in amniotic fluid $(16,38)$. If, as we postulate, the delay in pulmonary maturation in IDM is a result of diminished alveolar concentrations of DSPC, this diminution may be reflected in amniotic fluid. Measurement of amniotic fluid DSPC might then prove to be a better predictor of pulmonary maturation in the diabetic pregnancy.

Our rabbit model of diabetes during pregnancy has several features in common with those observed in the human diabetic pregnancy: maternal and fetal hyperglycemia, maternal insulinopenia, fetal pulmonary instability on deflation consistent with RDS, and an apparent increased incidence of congenital anomalies and fetal wastage. The fetuses of diabetic does, however, did not demonstrate hyperinsulinism or overgrowth. These particular inconsistencies have been reported by other investigators in subprimate models of the diabetic pregnancy (39-41). The fact that glucose is not a potent insulin secretogogue during fetal life (42) may explain the lack of hyperinsulinism in the fetuses of the alloxan-treated does. Since the gestation of the rabbit is short and since rabbit pups are born before a gestational period of rapid growth, comparable to the third trimester of human gestation, it is possible that there is insufficient time during gestation for fetal overgrowth to occur. Nonetheless, this model of the diabetic pregnancy appears to be a useful and practical model with which to study the effects of maternal diabetes on pulmonary maturation in the fetus.

\section{ACKNOWLEDGMENTS}

We thank Dr. Louis Underwood for consultation and the use of his insulin antibody, Dr. Ernest Kraybill for editorial advice, and Ms. Cora Jane Pope for assistance in manuscript preparation.

This work was supported by a research grant from the American Lung Association (Dr. Lawson), a Biomedical Research support grant (5-S07RR05406) from the National Institutes of Health (Dr. Lawson), and a Basil O'Connor Starter Research Grant (5-188) from the National Foundation (Dr. D'Ercole).

\section{REFERENCES}

1. Gellis, S. S., and D. Y. Hsia. 1959. The infant of the diabetic mother. Am. J. Dis. Child. 97: 1-41.

2. Robert, M. F., R. K. Neff, J. P. Hubbell, H. W. Taeusch, and M. E. Avery. 1976. Association between maternal diabetes and the respiratory distress syndrome in the newborn. N. Engl. J. Med. 294: 357-360.

3. Avery, M. E., and J. Mead. 1959. Surface properties in relation to atelectasis and hyaline membrane disease. Am. J. Dis. Child. 97: 517-523.

4. Gluck, L., M. V. Kulovich, R. C. Borer, P. H. Brenner, G. C. Anderson, and W. N. Spellacy. 1971. Diagnosis of the 
respiratory distress syndrome by amniocentesis. Am. J. Obstet. Gynecol. 109: 440-445.

5. Dahlenburg, G. W., F. I. R. Martin, P. R. Jeffrey, and I. Horacek. 1977. Amniotic fluid lecithin/sphingomyelin ratio in pregnancy complicated by diabetes. Br.J. Obstet. Gynaecol. 84: 294-299.

6. Hildebran, J. N., J. Goerke, and J. A. Clements. 1979. Pulmonary surface film stability and composition.J. Appl. Physiol. 47: 604-611.

7. Gluck, L., R. A. Landowne, and M. V. Kulovich. 1970. Biochemical development of surface activity in mammalian lung. III. Structural changes in lung lecithin during development of the rabbit fetus and newborn. Pediatr. Res. 4: 352-364.

8. Wellmann, K. F., B. W. Volk, S. S. Lazarus, and P. Brancato. 1969. Pancreatic/ $\beta$ cell morphology and insulin content of normal and alloxan-diabetic rabbits and their offspring. Diabetes. 18: 138-145.

9. Sosenko, I. R. S., E. E. Lawson, V. Demottaz, and I. D. Frantz. 1980. Functional delay of lung maturation in fetuses of diabetic rabbits. J. Appl. Physiol. Respir. Environ. Exercise Physiol. 48: 643-647.

10. Kotas, R. V., and M. E. Avery. 1971. Accelerated appearance of pulmonary surfactant in the fetal rabbit. $J$. Appl. Physiol. 30: 358-361.

11. Folch, J., M. Lees, and G. H. Sloane-Stanley. 1957. A simple method for the isolation and purification of total lipids from animal tissues. J. Biol. Chem. 226: 497-509.

12. Carroll, J. J., N. Smith, and A. L. Babson. 1970. A colorimetric serum glucose determination using hexokinase and glucose-6-phosphate dehydrogenase. Biochem. Med. 4: 171-180.

13. Voina, S., L. E. Underwood, and J. J. VanWyk. 1971. Failure of leucine, arginine and epinephrine to alter plasma insulin levels in vitro. Horm. Metab. Res. 3: 127-128.

14. Bartlett, G. R. 1959. Phosphorus assay in column chromatography. J. Biol. Chem. 234: 466-468.

15. Mason, R. J., J. Nellenbogen, and J. A. Clements. 1976. Isolation disaturated phosphatidyl choline with osmium tetroxide. J. Lipid Res. 17: 281-284.

16. Torday, J., L. Carson, and E. E. Lawson. 1979. Saturated phosphatidyl choline in amniotic fluid and prediction of RDS. N. Engl. J. Med. 301: 1013-1018.

17. Rooney, S. A., L. L. Nardone, D. L. Shapiro, E. K. Motoyama, and L. Gobran. 1977. The phospholipids of rabbit type II alveolar epithelial cells: comparison with lung lavage, lung tissue, alveolar macrophage, and a human alveolar tumor cell line. Lipids. 12: 438-442.

18. Lawson, E. E., R. L. Birdwell, P. S. Huang, and H. W. Taeusch. 1979. Augmentation of pulmonary surfactant secretion by lung expansion at birth. Pediatr. Res. 13: 611-614.

19. Abbey, H., and E. Howard. 1973. Statistical procedure in developmental studies on species with multiple offspring. Dev. Psychobiol. 6: 329-335.

20. Chang, M. C. 1951 . Fertility and sterility as revealed in the study of fertilization and development of rabbit eggs. Fertil. Steril. 2: 205-222.

21. Bruckmann, G., and E. Wertheimer. 1947. Alloxan studies. The action of alloxan homologues and related compounds. J. Biol. Chem. 168: 241-256.

22. Bencosme, S. A. 1955. The histogenesis and cytology of the pancreatic isleis in the rabbit. Am. J. Anat. 96: 103-151.

23. Kikkawa, Y., E. K. Motoyama, and L. Gluck. 1968. Study of the lungs of fetal and newborn rabbits. Am. J. Pathol. 52: 117-209.
24. Friedgood, C. E., and A. A. Miller. 1945. Alloxan in pregnant rats. Proc. Soc. Exp. Biol. Med. 59: 61-62.

25. Brumley, G. W., V. Chernick, W. A. Hodson, C. Normand, A. Fenner, and M. E. Avery. 1967. Correlations of mechanical stability, morphology, pulmonary surfactant, and phospholipid content in the developing lamb lung. $J$. Clin. Invest. 46: 863-873.

26. Taeusch, H. W., I. Wyszogrodski, N. S. Wang, and M. E. Avery. 1974. Pulmonary pressure-volume relationships in premature fetal and newborn rabbits.J. Appl. Physiol. 37: 809-813.

27. Corbet, A. J., P. Flax, C. Alston, and A. J. Rudolph. 1978. Effects of aminophyllin and dexamethasone on secretion of pulmonary surfactant in fetal rabbits. Pediatr. Res. 12: 797-799.

28. Gruenwald, P. 1963. Normal and abnormal expansion of the lungs of newborn infants obtained at autopsy. II. Opening pressure, maximal volume, and stability of expansion. Lab. Invest. 12: 563-576.

29. Obladen, M., Merritt, T. A., and L. Gluck. 1979. Acceleration of pulmonary surfactant maturation in stressed pregnancies: A study of neonatal lung effluent. Am. J. Obstet. Gynecol. 135: 1079-1085.

30. Gluck, L., Sribney, M., and M. V. Kulovich. 1967. The biochemical development of surface activity in mammalian lung. Pediatr. Res. 1: 247-265.

31. Rooney, S. A., Wai-Lee, T. S., Gobran, L., and E. K. Motoyama. 1967. Phospholipid content, composition and biosynthesis during fetal lung development in the rabbit. Biochim. Biophys. Acta. 431: 447-458.

32. Hallman, M., and L. Gluck. 1976. Phosphatidylglycerol in lung surfactant. III. Possible modifier of surfactant function. J. Lipid Res. 17: 257-262.

33. Kulovich, M. V., and L. Gluck. 1979. The lung profile. II. Complicated pregnancy. Am. J. Obstet. Gynecol. 135: 64-70.

34. Smith, B. T., C. J. P. Giroud, M. Robert, and M. E. Avery. 1975. Insulin antagonism of cortisol action on lecithin synthesis by cultured fetal lung cells. J. Pediatr. 87: 953-955.

35. Isles, T. E., M. Dickson, and J. W. Farquhar. 1968. Glucose tolerance and plasma insulin in newborn infants of normal and diabetic mothers. Pediatr. Res. 2: 198-208.

36. Gross, I., and G. J. W. Smith. 1977. Insulin delays in morphologic maturation of fetal rat lung in vitro. Pediatr. Res. 11: 515. (Abstr.)

37. Sosenko, I. R., J. L. Kitzmiller, S. W. Loo, P. Blix, A. H. Rubenstein, and K. H. Gabbay. 1979. The infant of the diabetic mother. Correlation of increased cord C-peptide levels with macrosomia and hypoglycemia. N. Engl. J. Med. 301: 859-862.

38. Kulovich, M., M. Hallman, and L. Gluck. 1979. The lung profile. I. Normal pregnancy. Am. J. Obstet. Gynecol. 135: 57-63.

39. Aerts, L., and F. A. Van Assche. 1977. Rat foetal endocrine pancreas in experimental diabetes. J. Endocrinol. 73: 339-346.

40. Pitkin, R. M., and D. E. Van Order. 1974. Fetal effects of maternal stretozotocin-diabetes. Endocrinology. 94: $1247-1253$.

41. Sybulski, S., and G. B. Maughan. 1971. Use of streptozotocin as diabetic agent in pregnant rats. Endocrinology. 89: 1537-1540.

42. Fisher, D. A. 1976. Insulin and carbohydrate metabolism. In The Physiology of the Newborn Infant. C. A. Smith and N. M. Nelson, editors. Charles C Thomas, Springfield, Ill. 584-612. 